\title{
深圳冬、夏季大气细粒子及其二次组分的 污染特征
}

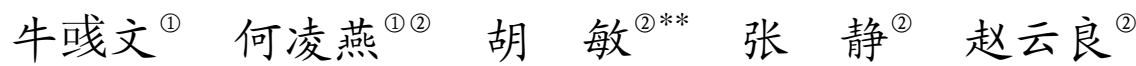 \\ (1) 北京大学深圳研究生院环境与城市学院, 深圳 518055; (2) 北京大学环境学院 环境模拟 \\ 与污染控制国家联合重点实验室，北京 100871)
}

\begin{abstract}
摘要在 2004 年夏季和冬季, 分别在深圳宝安中心区进行了大气颗粒物细粒子的加强观测, 共获得 30 套样品. 通过对样品质量浓度、化学成分分析, 结合采样期间的气象条件, 对深圳当前 大气颗粒物的污染特征、季节变化规律(夏季和冬季)及二次污染特征进行了研究. 结果表明, 深 圳大气颗粒物污染的季节差异较大, 在夏季加强观测期间, $\mathrm{PM}_{2.5}$ 和 $\mathrm{PM}_{10}$ 的日均质量浓度分别为 $34.9 \mu \mathrm{g} \cdot \mathrm{m}^{-3}$ 和 $56.9 \mu \mathrm{g} \cdot \mathrm{m}^{-3}$; 冬季加强观测期间 $\mathrm{PM}_{2.5}$ 和 $\mathrm{PM}_{10}$ 的日均质量浓度分别为 $99.0 \mu \mathrm{g} \cdot \mathrm{m}^{-3}$ 和 $134.8 \mu \mathrm{g} \cdot \mathrm{m}^{-3}$, 分别比夏季增长 $184 \%$ 和 $137 \% . \mathrm{PM}_{2.5}$ 在夏季和冬季观测期间平均分别占 $\mathrm{PM}_{10}$ 的 61\%和 73\%, 细粒子污染严重; 夏、冬季加强观测期间 OC 和 EC 的比值平均分别为 3.4 和 1.6, 估算的 SOC 占 OC 的比例平均分别为 $56 \%$ 和 $6 \%$, 夏季 SOC 对 OC 的贡献显著; 在夏季持续高温 期间, 二次颗粒物的浓度及其在 $\mathrm{PM}_{2.5}$ 中的比重都急剧升高, 本地二次污染严重; 当夏季主导风 向来自西南或东南海面时, 大气环境质量较好, 冬季主导风向来自北方内陆时, 大气环境质量较 差.
\end{abstract}

\section{关键词 $\quad \mathbf{P M}_{2.5}$ 质量浓度 二次污染 季节变化 深圳市}

大气颗粒物细粒子 $\mathrm{PM}_{2.5}$ (空气动力学直径小于 $2.5 \mu \mathrm{m})$ 直接影响到大气环境质量、大气能见度和人 体健康 ${ }^{[1]}$, 成为当前国内外许多城市面临的重要环境 问题. 从 20 世纪 80 年代起, 对于 $\mathrm{PM}_{2.5}$ 的研究和防治
受到了美国和一些欧洲国家的广泛重视, 美国环保 局在 1997 年率先颁布了 $\mathrm{PM}_{2.5}$ 的空气质量标准, 年均 值 $15.0 \mu \mathrm{g} \cdot \mathrm{m}^{-3}$, 日均值 $65.0 \mu \mathrm{g} \cdot \mathrm{m}^{-31)}$; 我国从 20 世 纪 90 年代逐渐对 $\mathrm{PM}_{2.5}$ 展开研究, 在北京、上海、南

收稿日期: 2005-08-11; 接受日期: 2006-01-03

* 国家重点基础研究发展规划(973)(2002CB211605)、国家自然科学基金(批准号: 20420130348, 40490260)和广东省自然科学基金(04300640)资 助项目

** 联系人, E-mail: minhu@pku.edu.cn

1) US EPA Office of Air and Radiation, Office of Air Quality Planning and Standards Fact Sheet-EPA's Recommended Final Ozone and Particulate Matters Standards. 1997. http://www.epa.gov//ttn/oarpg/naaqsfin/03pm.html 
京、广州等大陆主要城市 ${ }^{[2 \sim 13]}$ 以及香港的研究 ${ }^{[14 ~ 16]}$ 表 明 $\mathrm{PM}_{2.5}$ 的质量浓度和主要化学组分受季节变化影响 较大, 呈现冬季高夏季低的季节特点, 含碳物质和 $\mathrm{SO}_{4}^{2-}, \mathrm{NO}_{3}^{-}$以及 $\mathrm{NH}_{4}{ }^{+}$等水溶性离子是 $\mathrm{PM}_{2.5}$ 的主要组 成部分, $\mathrm{PM}_{2.5}$ 的质量浓度在我国各主要城市的年均 浓度在 57 160 $\mu \mathrm{g} \cdot \mathrm{m}^{-3}$ 之间 ${ }^{[4,6,12]}$, 高出美国环保局 1997 年推荐的 $\mathrm{PM}_{2.5}$ 年均质量浓度标准的 2.8 9.7 倍, $\mathrm{PM}_{2.5}$ 已成为影响我国城市大气环境质量的主要污染 物之一。

深圳作为珠三角城市群中连接香港和内陆的枢 纽, 在 1997 年被率先评为我国的环境保护模范城市, 其大气环境质量优于周边城市，由于其在珠三角特 殊的地理位置, 在一定程度上反映了大气污染的区 域性特点以及内陆和香港间大气污染物的传输. 近 年来随着珠三角城市群工业化进程的加快, 深圳本 地工业燃料消耗量及机动车数量的快速增长(2001 年 到 2004 年年均增长率达 $18.7 \%, 2004$ 年深圳机动车已 超过 62 万辆), 深圳大气中 $\mathrm{SO}_{2}, \mathrm{NO}_{2}$ 和 $\mathrm{PM}_{10}$ 的浓度 呈逐年上升的趋势 1$)$, 大气能见度在下降, 灰䨪天气 经常出现, 大气环境质量有恶化的趋势. 此外, 深圳 是典型的季风气候, 夏季盛行海风, 而冬季主要受来 自北方内陆污染较重的气团控制, 其大气环境质量 在不同季节差异很大. 目前对深圳大气细粒子研究 的文献报道非常少见，本研究在 2004 年夏季和冬季 对与工业污染较为严重的东莞、惠州等市比邻的以及 工厂企业密集的宝安区进行了大气细粒子 $\mathrm{PM}_{2.5}$ 的加 强观测. 通过对细粒子的质量浓度、化学成分分析, 探讨深圳市大气细粒子的污染现状、季节变化特点、 二次污染特征及受区域污染的影响.

\section{1 采样与分析}

本研究的采样点位于深圳宝安区中心区, 宝安 区位于深圳市西北部，南接南山和福田两区，北连东 莞和惠州两市, 西临珠江口伶仃洋, 东濒大鹏湾, 临望香港新界、元朗, 是深圳的工业基地和连接周边 城市的重要枢纽, 能够真实反映深圳大气环境质量 受自身及周边城市经济快速发展的影响. 采样器架
设在距离地面约 $15 \mathrm{~m}$ 的楼顶, 周围没有明显的局地 污染源. 在 2004 年夏季(6 月 17 日至 7 月 1 日)和冬 季(11月 20 日至 12 月 4 日)分别对 $\mathrm{PM}_{2.5}$ 进行了为期 各 15 天的采集，采样时间为约 $24 \mathrm{~h}$ (每天中午 $12 ： 00$ 到第二天中午 $11 ： 30$ ).

采样器为大气颗粒物四通道采样器(美国Thermo Andersen), 总流量 $48 \mathrm{~L} \cdot \mathrm{min}^{-1}, 1$ 和 4 通道安装石英膜, 流量均为 $16.7 \mathrm{~L} \cdot \mathrm{min}^{-1}$, 其中一张采样后用美国 Sunset Laboratory Inc.碳分析仪分析有机碳(OC)和元 素碳(EC), 该仪器采用热光吸收原理, 是目前最先进 的EC和OC分析方法之一. 具体方法详见文献[17], 这里简要叙述一下分析校正过程. 工作程序: 截取 $1.45 \mathrm{~cm}^{2}$ 的石英膜样品在 $\mathrm{He}$ 气下程序升温到 $850^{\circ} \mathrm{C}$, 释放的有机化合物和热解产物(部分碳化为 EC) 被氧 化成 $\mathrm{CO}_{2} . \mathrm{CO}_{2}$ 和氢气混合被还原成 $\mathrm{CH}_{4}$, 用火焰离子 化检测器(FID) 定量检测 $\mathrm{CH}_{4}$. 此过程中挥发氧化的 是OC. 首次程序升温完成后, 炉子冷却到 $500^{\circ} \mathrm{C}$ 并把 载气转换成 $\mathrm{He} / \mathrm{O}_{2}$ 混合气, 再程序升温到 $900^{\circ} \mathrm{C}$, 此 过程中EC被氧化并进入氧化炉, EC的测量同OC. 通 过计算得到样品膜上OC和EC的质量浓度 $\left(\mu \mathrm{gC} \cdot \mathrm{cm}^{-2}\right)$. 在整个分析过程中, 采用 $\mathrm{He}-\mathrm{Ne}$ 激光进行热解校正, 通过石英膜的透光率确定 OC和EC的分割点. 分割点 之前所有峰面积积分为 OC, 之后的峰面积积分为EC. 2 和 3 通道安装Teflon膜, 流量均为 $7.3 \mathrm{~L} \cdot \mathrm{min}^{-1}$, 其中 一张用于测定 $\mathrm{PM}_{2.5}$ 质量浓度和离子组分. 采样前后 在恒温恒湿超净实验室内 (温度 $20 \pm 1^{\circ} \mathrm{C}$, 相对湿度为 $45 \% \pm 5 \%$ ) 用十万分之一天平测定采样膜质量, 得到 $\mathrm{PM}_{2.5}$ 的质量浓度, 然后用ICS-2500 离子色谱仪(美国 Dionex公司)分析水溶性阴阳离子，分析方法详见文 献[18]. 在夏季和冬季加强观测期间分别采集 1 套野 外空白, 操作程序和样品完全相同, 然后带回实验室 和样品同时分析，确保了样品从采集到分析的准确 性.

夏季采样时段是深圳夏季典型的高温晴朗天气， 主导风向为来自海上的西南风，冬季采样时段主导 风向为来自内陆的东北风, 气温相对较低, 大气混合 层高度较低. 夏、冬季采样时段能够较好地代表深圳

1) 中国环境科学研究院. 深圳市空气污染控制规划研究. 2005 
夏季和冬季的气候特点, 采集到的样品具有很好的 季节代表性. 本研究中 $\mathrm{SO}_{2}, \mathrm{NO}_{x}, \mathrm{O}_{3}(\mathrm{DOAS}$, 瑞士 OPSIS 公司)和 $\mathrm{PM}_{10}(\mathrm{RP} 1400 \mathrm{a}$, 美国 R\&P 公司)的日 常监测数据由深圳市环境监测站提供.

\section{2 结果与讨论}

\section{$2.1 \mathrm{PM}_{2.5}$ 和 $\mathrm{PM}_{10}$ 的质量浓度水平及季节变化}

夏季加强观测期间, $\mathrm{PM}_{2.5}$ 的日均质量浓度在 $17.2 \sim 111.0 \mu \mathrm{g} \cdot \mathrm{m}^{-3}$ 之间, 变化较大, 平均为 $34.9 \pm 19.9$ $\mu \mathrm{g} \cdot \mathrm{m}^{-3}$ ，低于 2002 年夏季广州和珠三角的平均水平， 接近香港和珠海的水平 ${ }^{[19]}$ (表 1); $\mathrm{PM}_{10}$ 的日均浓度在 30.0 142.0 $\mu \mathrm{g} \cdot \mathrm{m}^{-3}$ 之间, 平均为 $56.9 \pm 25.3 \mu \mathrm{g} \cdot \mathrm{m}^{-3}$, $\mathrm{PM}_{2.5}$ 占 $\mathrm{PM}_{10}$ 的 $48 \% \sim 78 \%$, 平均为 $61 \%$. 在 15 天的 加强观测期间, $\mathrm{PM}_{2.5}$ 的质量浓度只有两天超过美国 环保局的日均浓度标准 $\left(65.0 \mu \mathrm{g} \cdot \mathrm{m}^{-3}\right) ; \mathrm{PM}_{10}$ 质量浓度 全部低于国家二级标准 $\left(150.0 \mu \mathrm{g} \cdot \mathrm{m}^{-3}\right)$, 表明深圳夏 季颗粒物污染较轻, 大气环境质量较好, 在珠三角地 区属相对清洁的地区. 冬季加强观测期间, $\mathrm{PM}_{2.5}$ 日均 质量浓度在 $49.3 \sim 161.6 \mu \mathrm{g} \cdot \mathrm{m}^{-3}$ 之间, 平均为 $99.0 \pm$ $17.6 \mu \mathrm{g} \cdot \mathrm{m}^{-3}$, 高于 2001 年冬季的水平, 已接近 2001 年冬季广州的水平 ${ }^{[20]}$ (表 1); $\mathrm{PM}_{10}$ 日均浓度在 50.3 $221.5 \mu \mathrm{g} \cdot \mathrm{m}^{-3}$ 之间, 平均为 $134.8 \pm 27.5 \mu \mathrm{g} \cdot \mathrm{m}^{-3}, \mathrm{PM}_{2.5}$ 占 $\mathrm{PM}_{10}$ 的 $65 \%$ 98\%, 平均为 $74 \%$. 在 15 天的加强观 测期间, $\mathrm{PM}_{2.5}$ 除 11 月 26 日之外，其余各日的浓度都 高于美国环保局的浓度标准, $\mathrm{PM}_{10}$ 有 6 天超过国家二 级标准, 超标率达 $40 \%$. 冬季 $\mathrm{PM}_{2.5}$ 和 $\mathrm{PM}_{10}$ 的质量浓
度显著高于夏季, 平均分别是夏季的 2.8 和 2.4 倍, $\mathrm{PM}_{2.5}$ 在 $\mathrm{PM}_{10}$ 中的比重也远远高于夏季，并且高于广 州、香港、珠海及珠三角 2001 年冬季的平均水 平는 (表 1), 说明深圳冬季大气颗粒物污染严重, 大 气环境质量较差. 夏、冬季 $\mathrm{PM}_{2.5}$ 在 $\mathrm{PM}_{10}$ 中占较高比 重说明深圳大气颗粒污染以细粒子为主, 且冬季更 为突出, 因此, 深圳市在进行大气环境管理和防治时 应优先考虑对细粒子的控制.

\section{$2.2 \mathrm{PM}_{2.5}$ 中水溶性离子组分污染特征}

夏季和冬季加强观测期间, 表征二次污染的水 溶性离子 $\mathrm{SO}_{4}^{2-}, \mathrm{NO}_{3}^{-}, \mathrm{NH}_{4}^{+}$是 $\mathrm{PM}_{2.5}$ 中浓度较高的离子 组分. 三者总和在夏季平均占 $\mathrm{PM}_{2.5}$ 质量浓度的 $39 \%$, 冬季占 $38 \%$, 夏、冬季的比例接近, 但冬季的浓度水 平比夏季都有很大幅度的增长(图 1), $\mathrm{SO}_{4}^{2-}, \mathrm{NO}_{3}^{-}, \mathrm{NH}_{4}^{+}$ 的日均浓度平均分别比夏季增长 $177 \%, 475 \%$ 和 $97 \%$, 主要与冬季大气扩散条件变差, 混合层高度较低, 主 导风向为来自内陆污染气团有关. 其中 $\mathrm{SO}_{4}^{2-}$ 是浓度 最高的离子组分, 夏季和冬季加强观测期间平均浓 度分别为 8.6 和 $23.9 \mu \mathrm{g} \cdot \mathrm{m}^{-3}$, 分别占总水溶性离子的 $57 \%$ 和 $59 \%$, 占 $\mathrm{PM}_{2.5}$ 的 $25 \%$ 和 $24 \%$.

除 $\mathrm{SO}_{4}^{2-}, \mathrm{NO}_{3}^{-}, \mathrm{NH}_{4}^{+}$之外, $\mathrm{Cl}^{-}, \mathrm{F}^{-}, \mathrm{Na}^{+}, \mathrm{K}^{+}, \mathrm{Mg}^{2+}$, $\mathrm{Ca}^{2+}$ 等离子浓度的总和在夏季和冬季分别占总水溶 性离子的 $12 \%$ 和 $10 \%$, 分别占 $\mathrm{PM}_{2.5}$ 质量浓度的 $5 \%$ 和 $4 \%$, 夏季和冬季基本接近. 和夏季相比, 除 $\mathrm{Na}^{+}$略 有降低之外, 其他离子的浓度在冬季均有所升高. $\mathrm{K}^{+}$

表 12004 年夏、冬季加强观测期间深圳市 $\mathrm{PM}_{2.5}, \mathrm{PM}_{10}$ 浓度和 $\mathrm{PM}_{2.5} / \mathrm{PM}_{10}$ 比值与珠三角其他地区的比较

\begin{tabular}{|c|c|c|c|c|c|c|}
\hline 观测时间 & 季节 & 观测地点 & $\mathrm{PM}_{2.5}$ 浓度 $/ \mu \mathrm{g} \cdot \mathrm{m}^{-3}$ & $\mathrm{PM}_{10}$ 浓度/ $\mu \mathrm{g} \cdot \mathrm{m}^{-3}$ & $\mathrm{PM}_{2.5} / \mathrm{PM}_{10} / \%$ & 参考文献 \\
\hline 2004 年 & 夏季 & 深圳 & $34.9 \pm 19.9$ & $56.9 \pm 25.3$ & 61 & 本研究 \\
\hline \multirow[t]{5}{*}{2002 年 } & 夏季 & 香港 & $31.0 \pm 16.9$ & $41.4 \pm 14.2$ & 71 & [19] \\
\hline & & 广州 & $78.1 \pm 29.7$ & $124.7 \pm 55.5$ & 64 & [19] \\
\hline & & 深圳 & $47.1 \pm 16.7$ & $75.1 \pm 23.0$ & 63 & [19] \\
\hline & & 珠海 & $31.0 \pm 20.0$ & $44.0 \pm 24.8$ & 69 & $\underline{[19]}$ \\
\hline & & 珠三角平均水平 & $49.1 \pm 30.6$ & $74.6 \pm 51.2$ & 69 & $\underline{[19]}$ \\
\hline 2004 年 & 冬季 & 深圳 & $99.0 \pm 17.6$ & $134.8 \pm 27.5$ & 73 & 本研究 \\
\hline \multirow[t]{5}{*}{2001 年 } & 冬季 & 香港 & $54.5 \pm 22.9$ & $73.9 \pm 27.9$ & 72 & {$[20]$} \\
\hline & & 广州 & $105.9 \pm 71.4$ & $161.7 \pm 114.4$ & 68 & $\underline{[20]}$ \\
\hline & & 深圳 & $60.8 \pm 18.0$ & $83.7 \pm 27.4$ & 73 & [20] \\
\hline & & 珠海 & $59.3 \pm 23.7$ & $84.1 \pm 31.6$ & 71 & [20] \\
\hline & & 珠三角平均水平 & $72.6 \pm 49.0$ & $111.5 \pm 83.5$ & 70 & {$[20]$} \\
\hline
\end{tabular}




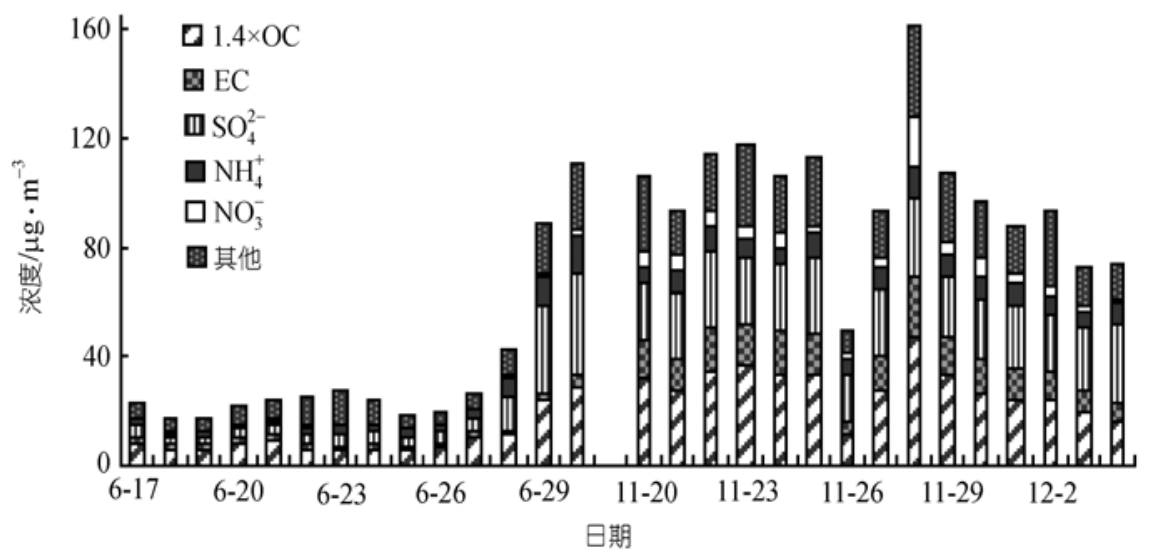

图 1 夏、冬季 $\mathrm{PM}_{2.5}$ 中 $\mathrm{SO}_{4}{ }^{2-}, \mathrm{NO}_{3}{ }^{-}, \mathrm{NH}_{4}{ }^{+}$及 $\mathrm{OC}, \mathrm{EC}$ 等化学组分的逐日变化 $1.4 \times \mathrm{OC}$ 代表有机物

浓度增幅最大，夏季 $\mathrm{K}^{+}$的平均浓度为 $0.42 \pm 0.34$ $\mu \mathrm{g} \cdot \mathrm{m}^{-3}$, 冬季为 $2.18 \pm 0.37 \mu \mathrm{g} \cdot \mathrm{m}^{-3}$, 冬季约是夏季的 5 倍, 并且在 $\mathrm{PM}_{2.5}$ 中的比重由夏季的 $1.7 \%$ 上升到冬 季的 $2.2 \%$. 生物质燃烧是城市大气颗粒物的一个重 要来源 16,21$], \mathrm{K}^{+}$通常被认为是生物质燃烧的标志物, 说明在冬季生物质燃烧对深圳大气 $\mathrm{PM}_{2.5}$ 的贡献更大.

\section{3 $\mathrm{PM}_{2.5}$ 中元素碳(EC)和有机碳(OC)的浓度水 平及二次有机碳(SOC)的估算}

\subsubsection{EC 和 $\mathrm{OC}$ 的浓度水平及季节变化}

夏季加强观测期间, $\mathrm{PM}_{2.5}$ 中 EC 和 OC 的日均浓 度在 $1.7 \sim 3.7$ 和 $4.0 \sim 20.6 \mu \mathrm{g} \cdot \mathrm{m}^{-3}$ 之间, 平均分别占 $\mathrm{PM}_{2.5}$ 质量浓度的 $6 \%$ 和 $21 \%$; 冬季 $\mathrm{EC}$ 和 $\mathrm{OC}$ 的日均
浓度在 4.9 21.8 和 8.2 33.5 $\mu \mathrm{g} \cdot \mathrm{m}^{-3}$ 之间, 平均分别 占 $\mathrm{PM}_{2.5}$ 质量浓度的 $13 \%$ 和 $20 \% . \mathrm{EC}, \mathrm{OC}$ 和 $\mathrm{PM}_{2.5}$ 质量 浓度的季节变化规律一致, 冬季浓度都有较大幅度 的升高, 分别是夏季 6 倍和 3 倍(表 2), 表明深圳冬季 含碳物质对大气环境的污染比夏季严重. 夏、冬季OC 和EC的比值差异较大, 夏季在 1.9 6.8 之间, 变化较 大, 平均为 3.4; 冬季在 1.5 1.8 之间, 平均为 1.6. EC 主要来自机动车尾气的直接排放, 其在大气环境中 性质比较稳定, 冬季浓度高于夏季, 主要与冬季大气 扩散条件变差有关. OC既有一次污染源的直接排放, 也可通过大气光化学反应生成

对夏冬季加强观测期间 EC 和 OC 的相关分析(图 2)表明, 冬季二者的相关性较好 $\left(R^{2}=0.98\right)$, 而夏季

表 22004 年夏季和冬季加强观测期间深圳市 EC 和 OC 的浓度水平与珠三角其他地区的比较

\begin{tabular}{|c|c|c|c|c|c|c|c|}
\hline 观测时间 & 季节 & 观测地点 & $\mathrm{EC}$ 浓度 $/ \mu \mathrm{g} \cdot \mathrm{m}^{-3}$ & $\mathrm{OC}$ 浓度/ $\mu \mathrm{g} \cdot \mathrm{m}^{-3}$ & OC/EC & $\mathrm{SOC} / \mu \mathrm{g} \cdot \mathrm{m}^{-3}$ & 参考文献 \\
\hline 2004 年 & 夏季 & 深圳 & $2.1 \pm 0.4$ & $7.2 \pm 3.4$ & 3.4 & 4.0 & 本研究 \\
\hline \multirow[t]{5}{*}{2002 年 } & 夏季 & 香港 & $3.2 \pm 2.6$ & $5.3 \pm 2.1$ & 1.9 & 2.2 & [19] \\
\hline & & 广州 & $5.9 \pm 2.1$ & $15.8 \pm 6.4$ & 2.7 & 9.3 & [19] \\
\hline & & 深圳 & $4.2 \pm 3.1$ & $7.6 \pm 4.9$ & 1.8 & 3.0 & [19] \\
\hline & & 珠海 & $1.9 \pm 0.9$ & $5.4 \pm 3.4$ & 2.9 & 3.4 & [19] \\
\hline & & 珠三角平均水平 & $4.1 \pm 2.7$ & $9.2 \pm 6.5$ & 2.5 & 4.9 & [19] \\
\hline 2004 年 & 冬季 & 深圳 & $12.7 \pm 3.1$ & $20.3 \pm 4.8$ & 1.6 & 1.2 & 本研究 \\
\hline \multirow[t]{5}{*}{2001 年 } & 冬季 & 香港 & $4.7 \pm 2.9$ & $9.6 \pm 4.5$ & 2.3 & 3.1 & $\underline{[20]}$ \\
\hline & & 广州 & $8.3 \pm 5.6$ & $22.6 \pm 18.0$ & 2.7 & 12.1 & $\underline{[20]}$ \\
\hline & & 深圳 & $6.1 \pm 1.8$ & $13.2 \pm 4.1$ & 2.2 & 5.8 & [20] \\
\hline & & 珠海 & $5.0 \pm 1.6$ & $12.2 \pm 4.4$ & 2.5 & 5.8 & [20] \\
\hline & & 珠三角平均水平 & $6.1 \pm 4.0$ & $14.7 \pm 11.9$ & 2.4 & 8.4 & [20] \\
\hline
\end{tabular}



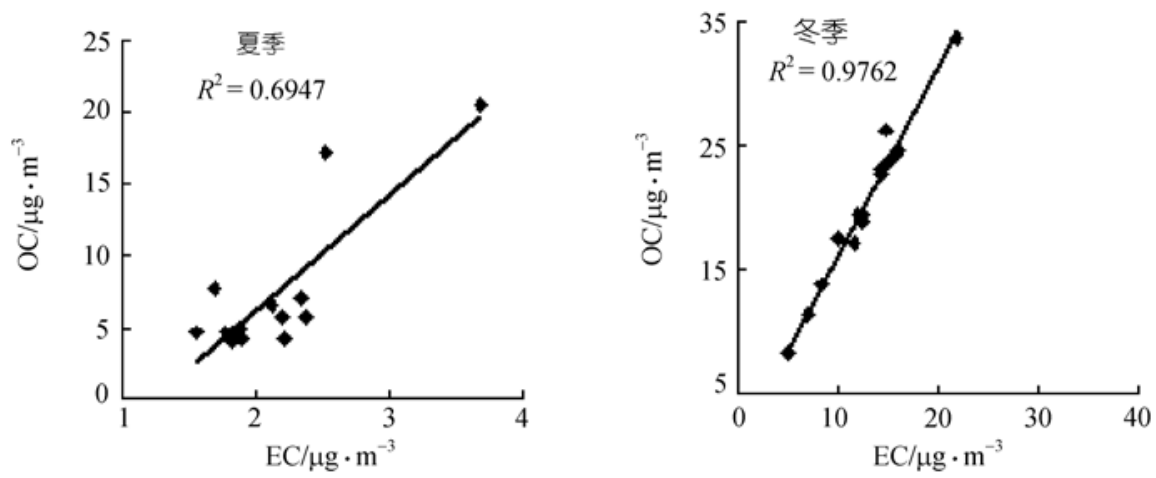

图 2 夏季和冬季观测期间深圳市 $\mathrm{PM}_{2.5}$ 中 EC 和 OC 的相关性

较差 $\left(R^{2}=0.69\right)$. 由此可以判断在冬季无论EC或OC 都主要来自汽车尾气排放, 因此相关性较好, 而夏季 光化学反应产生的SOC波动对OC变化的影响使EC与 $\mathrm{OC}$ 的相关性显著降低. 深圳夏季气温较高, 太阳辐 射强烈, 大气光化学反应活跃, 有利于SOC的生成. 2004 年冬季EC和OC的平均浓度比 2001 年冬季分别 增长约 1 倍和 0.5 倍, OC的浓度高于珠三角 2001 年 冬季的平均水平, 已接近有机污染较重的广州 2001 年冬季的水平(表 2) ${ }^{[20]}$, 说明深圳市含碳物质的污染 有加重的趋势, 这与近年来深圳本地机动车数量快 速增长, 机动车排放源向大气环境输入的含碳物质 的增加是直接相关的.

\subsection{2 二次有机碳(SOC)的估算}

SOC和大气能见度、气候及人体健康密切相

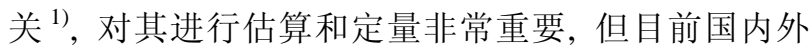
学术界对SOC的估算仍然存在很多争议, 尚未形成 统一的标准. Gray等在 1986 年 [23]曾采用OC和EC 的 比例来研究SOC的排放和形成特征, 利用 $\mathrm{OC}$ 和 EC的 最小比值来估算 $\mathrm{SOC}$ 的浓度. 通常认为当 $\mathrm{PM}_{2.5}$ 中 OC/EC的值超过 2.0 时就有SOC的存在 ${ }^{[23,24]}, 2004$ 年 夏季深圳 $\mathrm{PM}_{2.5}$ 中 $O C$ 和EC平均比值为 3.4 、冬季为 1.6. 本研究采用当前大多数学者估算 SOC 的方 法 ${ }^{[25]}$ 对 2004 年夏、冬季加强观测期间深圳 $\mathrm{PM}_{2.5}$ 中SOC的含 量进行了粗略的估算, 对其深入认识和准确定量还
有待进一步研究.

$$
\mathrm{OC}_{\mathrm{soc}}=\mathrm{OC}_{\mathrm{tot}}-\mathrm{EC}^{*}(\mathrm{OC} / \mathrm{EC})_{\min }^{[25]} \text {. }
$$

$\mathrm{OC}_{\mathrm{soc}}$ 表示二次有机碳(SOC); $\mathrm{OC}_{\mathrm{tot}}$ 表示总有机 碳; (OC/EC $)_{\min }$ 表示观测结果中 OC 与 EC 比值的最小 值, 本研究中观测到的 OC/EC 的最小值为 1.5 .

估算结果表明，夏季加强观测期间，SOC的浓度 在 $0.8 \sim 15.1 \mathrm{\mu g} \cdot \mathrm{m}^{-3}$ 之间, 变化较大, 平均为 4.0 $\mu \mathrm{g} \cdot \mathrm{m}^{-3}$ (表 2), 占OC的 19\% 78\%, 平均为 $56 \%$, 高于 Cao等人 ${ }^{[19]}$ 在 2002 年夏季对深圳大气中SOC占OC的 估算结果(44\%), 说明 2004 年夏季深圳大气 $\mathrm{PM}_{2.5}$ 中 SOC对OC贡献显著, 这与夏季观测后期出现的持续 高温有关; 冬季SOC的浓度在 $0 \sim 3.9 \mu \mathrm{g} \cdot \mathrm{m}^{-3}$ 之间, 平 均为 $1.2 \mu \mathrm{g} \cdot \mathrm{m}^{-3}$ (表 2), 占OC的 $0 \sim 15 \%$, 平均为 $6 \%$, 远远低于夏季的水平, 这与冬季气温低于夏季, 太阳 辐射强度减弱有关.

\section{4 夏、冬季加强观测期间 $\mathbf{P M}_{2.5}$ 质量浓度及其二 次组分浓度变化的影响因素}

在夏季加强观测前期(6 月 17 至 27 日), $\mathrm{PM}_{2.5}$ 质 量浓度, $\mathrm{SO}_{4}^{2-}, \mathrm{NO}_{3}^{-}, \mathrm{NH}_{4}^{+}$及其气态前体物和 $\mathrm{O}_{3}$ 的浓 度水平都较低, 从 6 月 28 日起到 30 日, 其浓度都突 然持续升高并在 30 日达到了最高值(图 1、图 3). 通 过 On-Line Hysplit_4 软件 ${ }^{2)}$ 进行反向轨迹计算表明: 6 月 17 日到 27 日深圳近地面气团主要来自西南和东南

1) Richard T, Hildemann L, Kamens R, et al. Secondary Organic Aerosols Research Strategy to Apportion Biogenic/Anthropogenic Sources: An Outcome of the First Secondary Aerosols Workshop, February4-5, 2002, Desert Research Institute, Reno, NV, Fort Lewis College, Durango, CO. http://www.wrapair.org/APACE/SOA/default.htm

2) http://www.arl.noaa.gov/ready/hysplit4.html 
方向的相对清洁的海面, 这是导致上述时段深圳大 气中污染物浓度较低的重要原因, 而从 6 月 28 日起 到 30 日, 风向变为来自东北内陆方向的气团, 此时, 深圳正好处于珠三角工业污染比较严重的惠州、东莞 等地的下风向，很可能有来自上述地区的污染物被 传输到深圳, 造成 6 月 28 日之后深圳大气中 $\mathrm{PM}_{2.5}$ 的质量浓度及二次水溶性离子及其气态前体物浓度 升高; 从天气情况及太阳辐射来看, 6 月 28 日后台风 “蒲公英” 在广东东南海面形成, 整个珠三角地区都 处于台风外围的下沉气流中, 污染物难以扩散; 此外, 6 月 28 日到 30 日深圳出现了历史罕见的持续高温天 气, 连续 3 天平均气温都在 $38^{\circ} \mathrm{C}$ 以上, 太阳辐射强烈, 大气光化学反映活跃, 为二次颗粒物和 $\mathrm{O}_{3}$ 的形成提供 了有利条件; 上述因素的综合作用导致 6 月 28 日到 30 日 $\mathrm{PM}_{2.5}$ 质量浓度及 $\mathrm{SO}_{4}^{2-}, \mathrm{NO}_{3}^{-}, \mathrm{NH}_{4}^{+}$浓度迅速升高.

冬季加强观测期间, $\mathrm{PM}_{2.5}$ 的质量浓度及 $\mathrm{SO}_{4}^{2-}$, $\mathrm{NO}_{3}^{-}, \mathrm{NH}_{4}^{+}$等主要化学组分的浓度比夏季都有大幅升 高, 而 $\mathrm{SO}_{2}$ 和 $\mathrm{NO}_{x}$ 的浓度和夏季基本接近(图 3), 说明 冬、夏季 $\mathrm{SO}_{4}^{2-}, \mathrm{NO}_{3}^{-}, \mathrm{NH}_{4}^{+}$的气态前体物浓度变化较 小, 冬季 $\mathrm{PM}_{2.5}$ 质量浓度及 $\mathrm{SO}_{4}^{2-}, \mathrm{NO}_{3}^{-}, \mathrm{NH}_{4}^{+}$的浓度升 高可能受气象条件和区域传输的影响较大. 一方面, 深圳冬季降雨量小, 大气混合层高度较低, 污染物清 除、扩散不如夏季; 另一方面，反向轨迹 ${ }^{1}$ 计算结果表 明，冬季加强观测期间深圳市主导风向一直为北 风和东北风, 来自深圳上风向地区(如东莞、惠州)的
污染物输入可能是导致深圳冬季 $\mathrm{PM}_{2.5}$ 质量浓度及 $\mathrm{SO}_{4}^{2-}, \mathrm{NO}_{3}^{-}, \mathrm{NH}_{4}^{+}$等浓度总体很高的重要原因. 从 $\mathrm{PM}_{2.5}$ 质量浓度及 $\mathrm{SO}_{4}^{2-}, \mathrm{NO}_{3}^{-}, \mathrm{NH}_{4}^{+}$的逐日浓度变化来 看, 11 月 26 日出现了观测期间的最低值, 11 月 28 日 出现了最高值. 气象数据表明, 在 11 月 26 日风速较 大(平均风速达 $3.1 \mathrm{~m} \cdot \mathrm{s}^{-1}$ ), 有利于污染物扩散, 可能 是该天各种污染组分浓度出现低值的重要原因; 26 日 的大风可能将大量的细粒子从深圳的上风向地区传 输到了深圳, 27 日、28 日风速较小(平均风速在 1.5 $\mathrm{m} \cdot \mathrm{s}^{-1}$ 以下), 污染物没有得到很好的稀释扩散, 此外, 11 月 28 日深圳出现了低空逆温层结, 污染物难以有 效扩散而在低空发生累积, 可能是 28 日出现重污染 日的重要原因.

夏、冬季加强观测期间 $\left(\mathrm{SO}_{4}^{2-}+\mathrm{NO}_{3}^{-}+\mathrm{NH}_{4}^{+}+\mathrm{SOC}\right)$ 在 $\mathrm{PM}_{2.5}$ 中的比重平均分别为 $41 \%$ 和 $39 \%$, 超过 $\mathrm{PM}_{2.5}$ 质量浓度的三分之一. 在城市大气中, $\mathrm{PM}_{2.5}$ 中 $\mathrm{SO}_{4}^{2-}$, $\mathrm{NO}_{3}^{-}, \mathrm{NH}_{4}^{+}$的一次来源贡献很小, 可以认为主要来自 二次转化. 在本研究中将 $\left(\mathrm{SO}_{4}^{2-}+\mathrm{NO}_{3}^{-}+\mathrm{NH}_{4}^{+}+\mathrm{SOC}\right)$ 称 为二次颗粒物，其夏、冬季在 $\mathrm{PM}_{2.5}$ 中比重较高表明 二次污染显著.

冬季 $\mathrm{PM}_{2.5}$ 中二次颗粒物的浓度总体上高于夏季, 这与冬季 $\mathrm{SO}_{4}^{2-}, \mathrm{NO}_{3}^{-}, \mathrm{NH}_{4}^{+}$的浓度高于夏季有关, 日均 浓度差异较小(图 4), 其变化主要受风速的影响较大, 最低值出现在风速较大的 11 月 26 日，最高值出现在 风速较小的 28 日. 夏季降水量大, 大气扩散条件较

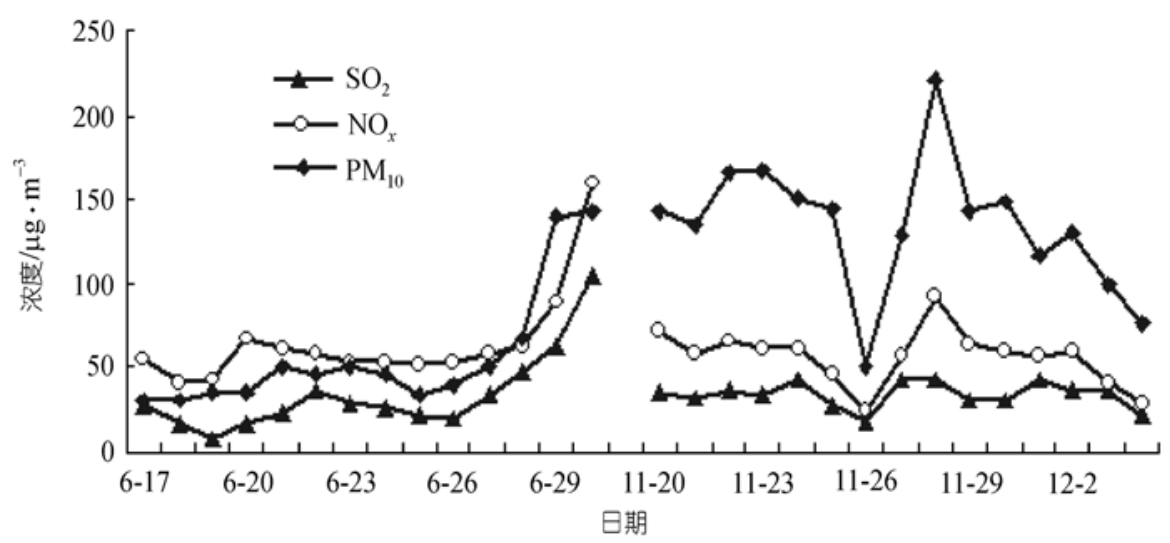

图 3 夏、冬季加强观测期间 $\mathrm{SO}_{2}, \mathrm{NO}_{x}$ 和 $\mathrm{PM}_{10}$ 浓度的逐日变化

1) 同 177 页脚注 2) 


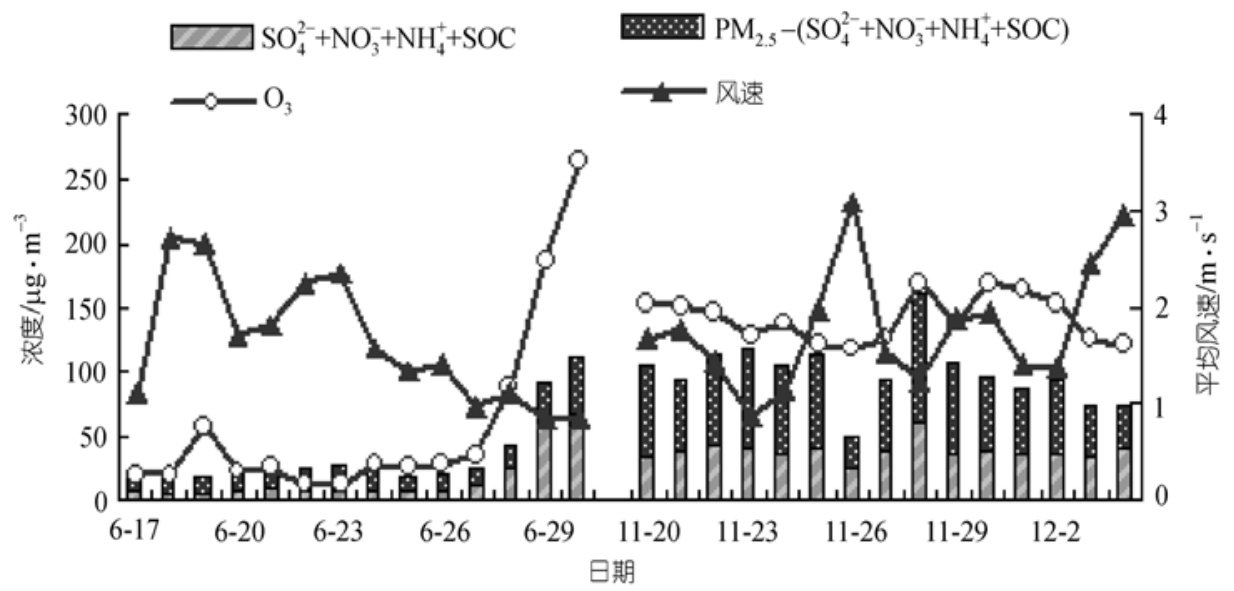

图 4 夏、冬观测期间 $\left(\mathrm{SO}_{4}^{2-}+\mathrm{NO}_{3}^{-}+\mathrm{NH}_{4}^{+}+\mathrm{SOC}\right)$ 的浓度及其在 $\mathrm{PM}_{2.5}$ 中比重及 $\mathrm{O}_{3}$ 浓度随风速的变化

好, 对二次颗粒物有较好的清除作用，在 6 月 17 日到 27 日, 气温相对稳定, 主导风向为来自海洋的清洁气 团，二次颗粒物浓度变化不大且总体上保持在较低 水平, 6 月 28 日到 30 日持续高温期间, 风向变为来自 北方的内陆气团, 二次颗粒物浓度及在 $\mathrm{PM}_{2.5}$ 中所占 的比重都突然持续升高(图 4), 28, 29, 30 日的浓度分 别比加强观测前期的平均水平 $\left(7.9 \mu \mathrm{g} \cdot \mathrm{m}^{-3}\right)$ 增长了 $214 \%, 624 \%$ 和 $760 \%$, 在 $\mathrm{PM}_{2.5}$ 中的比重分别达到了 $57 \%$, 64\%和 61\%, 分别超过观测前期平均比重(36\%) 的 58\%, 78\%, 69\%, 二次污染非常突出; $\mathrm{O}_{3}$ 浓度从 28 日起也迅速升高, 在 30 日达到了最高值 265.0 $\mu \mathrm{g} \cdot \mathrm{m}^{-3}$ (图 4), 超过国家二级标准 $\left(160 \mu \mathrm{g} \cdot \mathrm{m}^{-3}\right) 66 \%$, 说明高温期间大气光化学反应非常活跃; 6 月 17 27 日 SOC 的浓度在 $0.1 \sim 2.9 \mu \mathrm{g} \cdot \mathrm{m}^{-3}$ 之间, 变化较小, 而 从 28 日起也突然升高, 在 30 日达到了 $13.97 \mu \mathrm{g} \cdot \mathrm{m}^{-3}$, 是加强观测期间平均水平的 4 倍. 上述分析表明, 高 温天气较强的太阳辐射条件下活跃的大气光化学反 应对二次颗粒物和 SOC 浓度升高有重要影响, 导致 高温期间二次污染非常突出; 此外, 风向变化造成的 二次污染物的长距离输送可能也是 28 日之后二次颗 粒物浓度升高的原因之一. 冬季加强观测期间, SOC 的浓度总体上保持在较低水平, 其浓度变化主要受 风速风向等气象条件的影响较大.

\section{3 结论}

通过上述分析, 2004 年夏季和冬季加强观测期
间深圳大气细粒子的污染特征如下:

(i ) 深圳大气颗粒物污染的季节差异较大, 夏 季主导风向为来自南方海洋的清洁气团, 颗粒物浓 度总体较低, 大气环境质量较好; 冬季主导风向变为 来自北方内陆污染较重的气团, 颗粒物浓度较高, 大 气环境质量较差.

(ii) $\mathrm{PM}_{2.5}$ 在夏季和冬季平均分别占 $\mathrm{PM}_{10}$ 的 $61 \%$ 和 73\%, 细粒子污染严重; 冬季 $\mathrm{PM}_{2.5}$ 中 $\mathrm{K}^{+}$的平均浓 度是夏季的 5 倍, 在 $\mathrm{PM}_{2.5}$ 中的比重由夏季的 $1.7 \%$ 上 升到 $2.2 \%$, 说明冬季生物质燃烧源对深圳 $\mathrm{PM}_{2.5}$ 的贡 献更大.

(iii) $\mathrm{SO}_{4}^{2-}, \mathrm{NO}_{3}^{-}, \mathrm{NH}_{4}^{+}$是 $\mathrm{PM}_{2.5}$ 中含量较高的组分, 说明深圳二次污染显著.

(iv) OC 和 EC 二者之和在夏季和冬季分别占 $\mathrm{PM}_{2.5}$ 的 $23 \%$ 和 $33 \%$, 机动车排放源对深圳市大气环 境质量的影响不容忽视; 夏季 OC 与 EC 的比值甚高 于冬季, 夏季 SOC 对 OC 的贡献显著; 在夏季持续高 温期间, 二次颗粒物的浓度及其在 $\mathrm{PM}_{2.5}$ 中所占的比 重都急剧升高, $\mathrm{O}_{3}$ 超标严重, 本地二次污染非常突出.

致谢感谢中国环境科学研究院和深圳市环境监测 站对本研究的大力支持.

\section{参 考 文 献}

1 Chan Y C, Simpson R W, Mctainsh G H, et al. Characterization of chemical species in $\mathrm{PM}_{2.5}$ and $\mathrm{PM}_{10}$ aerosols in Brisbane, Australia. Atmospheric Environment, 1997, 31: 3773 3785[DOI]

2 杨复沫, 贺克斌, 马永亮, 等. 北京 $\mathrm{PM}_{2.5}$ 浓度的变化特征及其 
与 $\mathrm{PM}_{10}, \mathrm{TSP}$ 的关系. 中国环境科学, 2002, 22(6): 506 510

3 Zheng M, Slamon L G, Schauer J J, et al. Seasonal trends in $\mathrm{PM}_{2.5}$ source contributions in Beijing, China. Atmospheric Environment, 2005, 39: 3967 3976[DOI]

4 He K B, Yang F M, Ma Y L, et al. Characteristics of $\mathrm{PM}_{2.5}$ in Beijing, China. Atmospheric Environment, 2001, 35: 4959 4970[DOI]

5 Yao X H, Chan C K, Fang M, et al. The water-soluble ionic composition of $\mathrm{PM}_{2.5}$ in Shanghai and Beijing, China. Atmospheric Environment, 2002, 36: 4223 4234[DOI]

6 Ye B M, Ji X L, Yang $\mathrm{H} \mathrm{Z}$, et al. Concentration and chemical composition of $\mathrm{PM}_{2.5}$ in Shanghai in one-year period. Atmospheric Environment, 2003, 37: 499 510[DOI]

7 Wang G H, Huang L M, Gao S X, et al. Characterization of water-soluble species of $\mathrm{PM}_{10}$ and $\mathrm{PM}_{2.5}$ aerosols in urban area in Nanjing, China. Atmospheric Environment, 2002, 36: 1299 1307[DOI]

8 Yang H, Yu J Z, Ho S S H, et al. The chemical composition of inorganic and carbonaceous materials in $\mathrm{PM}_{2.5}$ in Nanjing, China. Atmospheric Environment, 2005, 39: 3735 3749[DOI]

9 王 荟, 王格慧, 黄鹂鸣, 等. 南京市大气中 $\mathrm{PM}_{10}, \mathrm{PM}_{2.5}$ 日污 染特征. 重庆环境科学, 2003, 25(5): 54 56

10 王 珢, 胡 敏. 青岛沿海地区大气气溶胶浓度与主要无机化 学组成. 环境科学, 2001, 22(1): 6 9

11 吴国平, 胡 伟, 滕恩江, 等. 我国四城市空气中 $\mathrm{PM}_{2.5}$ 和 $\mathrm{PM}_{10}$ 的污染水平. 中国环境科学, 1999, 19(2): 133 137

12 魏复盛, 滕恩江, 吴国平, 等.我国 4 个大城市空气 $\mathrm{PM}_{2.5}, \mathrm{PM}_{10}$ 污染及其化学组成. 中国环境监测, 2001, 17(7): 1 6

13 李龙凤，王新民，赵丽容，等. 广州市街道环境 $\mathrm{PM}_{10}$ 和 $\mathrm{PM}_{2.5}$ 质量浓度变化特征. 地球与环境, 2005, 33(2): 57 60

14 Pathak R K, Yao X H, Lau A K, et al. Acidity and concentrations of ionic species in $\mathrm{PM}_{2.5}$ in Hong Kong. Atmospheric Environment, 2003, 37: 1113 1124[DOI] species in $\mathrm{PM}_{2.5}$ and $\mathrm{PM}_{10}$ aerosols in Hong Kong. Atmospheric Environment, 2003, 37: 31 39[DOI]

16 Louie P K K, Watson J G, Chow J C, et al. Seasonal characteristics and regional transport of $\mathrm{PM}_{2.5}$ in Hong Kong. Atmospheric Environment, 2005, 39: 1695 -1710

17 刘新民，邵 敏，曾立明，等. 珠江三角洲地区气溶胶中含碳物 质的研究. 环境科学, 2002, 23(12): 54 59

18 胡 敏, 赵云良, 何凌燕, 等. 北京夏、冬季颗粒物及其离子成 分质量浓度谱分布. 环境科学, 2005, 26(4): 1 6

19 Cao J J, Lee S C, Ho K F, et al. Spatial and seasonal variations of atmospheric organic carbon and elemental carbon in Pearl River Delta Region, China. Atmospheric Environment, 2004, 38: 4447 4456[DOI]

20 Cao J J, Lee S C, Ho K F, et al. Characteristics of carbonaceous aerosols in Pearl River Delta region, China in 2001 winter period. Atmospheric Environment, 2003, 37: 1451 1460[DOI]

21 Duan F K, Liu X D, Yu T, et al. Identification and estimate of biomass burning contribution to the urban aerosol organic carbon concentrations in Beijing. Atmospheric Environment, 2004, 38: 1275 1282[DOI]

22 Seinfeld J H, Pandis S N. Atmospheric Chemistry and Physics: From Air Pollution to Climate Change. New York: Wiley Interscience, 1998. 700 703

23 Gray H A, Cass G R, Huntzicker J J, et al. Characteristics of atmospheric organic and elemental carbon particle concentrations in Los Angeles. Environment Science and technology, 1986, 20(6): 580 589[DOI]

24 Chow J C, Watson J G, Lu Z, et al. Descriptive analysis of $\mathrm{PM}_{2.5}$ and $\mathrm{PM}_{10}$ at regionally representative locations during SJVAQS/ AUSPEX. Atmospheric Environment, 1996, 30: 2079 2112[DOI]

25 Castro L M, Pio C A, Harrison R M, et al. Carbonaceous aerosol in urban and rural European atmospheres: estimation of secondary organic carbon concentrations. Atmospheric Environment, 1999, 33: 2771 2781[DOI] 